\title{
Locating and Retrieving Information
}

\section{Abstract}

After completing this learning unit, you will be able to:

- Identify real examples of documents;

- Argue about the need to process information and documents; and

- Exercise teamwork skills.

\section{Keywords}

Informational sources - Type of documents - Document processing

\subsection{Traditional Information Sources-Libraries}

A library's document or publication catalogue is an assembly of items organised according to certain criteria (such as content, or form) having the purpose of being used for information and documentation.

A work is an assembly consisting of information support, the data recorded within and its significance are meant for consulting, study, evidence etc.

A primary work is created by practical activity and contains original ideas, solutions, calculations, interpretations and such like.

The main elements of a primary work are: author, co-author, title, short title, preface, introduction, content, chapter, note, afterword, annex etc.

There are two kinds of primary works:

- Non-periodic primary works including: brochure, book (treatise, monograph, handbook etc.), tribute volume, glossary, dictionary, map, atlas, album, standard, pattern, publications of congresses, conferences, meetings, symposia, report (research report, press report, journey report), Ph.D. thesis, scientific 
communication, project, shopping catalogue, leaflet, technical documentation, regulatory documentation, specification, graphics, and audiovisual materials.

- Periodic primary works including: periodical (article, editorial, supplement), journal, newspaper, yearbook, address book, almanac, and calendar.

A secondary work is created by information and/or data classification from one or more primary works and contains their identifying features.

The main types of secondary documents include:

- Annotation;

- Bibliography (analytical bibliography, hidden bibliography, cumulative bibliography, current bibliography, bibliography of references, recommended bibliography, open literature, general bibliography, national bibliography, topic literature, retrospective bibliography, selective bibliography, special bibliography);

- Catalogue (alphabetic catalogue according to authors' names and titles, collective catalogue, numeric access catalogue, library catalogue, systematic catalogue);

- Compendium;

- Encyclopedia;

- Catalogue sheet (document-sheet, term-sheet etc.);

- Guide, index (publication index, alphabetic index, cumulative index, authors' index, pattern's index, citations index, formulas index, titles index by permutation, periodical index, systematic index);

- Lexicon; and

- Review, essay (analytic essay, indicative essay), reference, essays' journal, titles journal, abstract (author's abstract), and documentary synthesis.

\subsection{Cataloguing}

Item cataloguing, and implicitly item information, comprises the entire number of operations performed to organise items so that they can be retrieved and assessed. The main forms of analytical and synthetic item cataloguing include: bibliographic description, content classification and index, annotation, essays and articles.

Elements of publication cataloguing are presented in order to familiarise the reader with them, as they will be used later to retrieve information.

\subsubsection{Bibliographic Description}

A bibliographic description is made for all categories of works, specifying the necessary elements for characterising and identifying the types of works, which are 
part of libraries' collections and should be applied in item cataloguing both for manual systems and automated systems.

\subsubsection{Descriptive Features}

Bibliographic description for a library catalogue consists of the following bibliographic features, characteristic to each item, required for identification and differentiation:

- Star;

- Star author;

- $\quad$ Title heading;

- Description or descriptive note body;

- Title;

- Alternative title;

- Collective title;

- Joined title;

- Multilingual title;

- Parallel title;

- Caption or title information;

- Edition particularities;

- $\quad$ Issuing or publishing data;

- Collation;

- Quantity characterisation;

- Format;

- Series or collection; and

- Notes and observations of cataloguer.

Traditional catalogues are catalogues including mobile cards with bibliographic description of publications. The description is made according to the International Standard of Bibliographic Description (ISBD).

\subsubsection{Classification}

A classification is an operation of "arranging books or their description in the most advantageous manner for the readers" and responds to a logical need of ordering human thought.

A classification is an intellectual process, a logical operation of grouping objects according to their degree of similarity and of separation according to their degree of 
differentiation. It is the operation that helps determine the class to which a work belongs in order to distribute materials on domains, considering the content, so that they can be retrieved. However it is not only a general grouping of topics, but also involves arranging them in a logical order to establish a relationship among topics.

The purpose of classification is to make information available to the user in due time.

Classification consists of the systematic division into classes according to thematic content.

The main library classification systems are:

- Universal Decimal Classification;

- Dewey Decimal Classification;

- Bliss Bibliographic Classification;

- USA Congress Library Classification;

- Colon Classification of Ranganatan; and

- Cutter Classification.

The Universal Decimal Classification is a systematic classification scheme based on the decimal division principle of all human knowledge. Universal Decimal Classification (U.D.C.) represents a systematic classification scheme used in libraries as a general scheme of ordering all domains of human knowledge, by using a decimal form notation to represent items' topics. The development of (U.D.C.) scheme is based upon a hierarchic principle, starting from general to particular; each of the components are divided in a decimal system, reaching different levels of structure representation: classes, divisions, subdivisions. ("UDC Consortium About UDC”. 2019. Udcc.Org. Accessed February 15 2019. http://www.udcc.org/ index.php/site/page?view=about).

UDC, therefore, includes the following main classes:

- 0.0 Generalities. Science and knowledge. Organisation. Information. Documentation. Library science. Institutions. Publications.

- 0.1 Philosophy. Psychology.

- 0.2 Religion. Theology

- 0.3 Social sciences. Statistics. Politics. Economics. Trade. Law. Administration. Military art. Insurance. Education. Ethnography. Folklore.

- 0.4 Free.

- 0.5 Mathematics and natural sciences.

- 0.6 Applied sciences. Medicine. Technical.

- 0.7 Arts. Recreation. Entertainment. Sport.

- 0.8 Language. Linguistics. Literature.

- 0.9 Geography. Biography. History.

In a traditional library UDC is used to create the systematic catalogue and to arrange collections on shelves. In a computerised library it is used especially for organising the catalogue of open access collections, as also shelf access. 


\subsubsection{Indexing}

It is a process of describing and expressing the content of a work with the help of some specific terms called descriptors.

Specific terms are studied in terms of their linguistic aspect (grammar and semantic form), scientific aspect, and frequency of use aspect, using specialised programs able to select, systematise and validate the use in the indexing process of only some terms that will become descriptors.

Until these programs emerged, this selection and validation effort was exclusively the work of some groups consisting of linguists and librarians specialised in processing certain sciences and subjects. Currently this task is generally committed to national bibliographic agencies (national libraries) or national centers for information and documentation.

All terms established this way create the indexing language, which is a classification language with a specific syntax. Principles and rules used to select and validate descriptors and also the rules of item and information indexing are the subject of some international standards developed in order to ensure unity and consistency to the information classification process.

The assembly of descriptors in a certain language represents an indexing instrument called thesaurus.

\subsubsection{Thesaurus}

Is a standard list of descriptors, alphabetically ordered, indicating semantic and logical relationships (hierarchic and associative).

Descriptors are unique accepted forms, therefore authoritative, and for this reason controlled vocabularies and thesauri are known in library-science literature as a list of authorities.

Thesaurus or list of authorities' functions:

- Ensures the control of descriptor's use at the level of content description;

- Allows the interrogation of an online catalogue (bibliographic database) in a natural language that the thesaurus translates into a classification language (allows also interrogation with excluded terms);

- Facilitates "navigation" within a search with specific and generic questions;

- Ensures completion of a search by investigations and on the associated term; and

- Ensures a good understanding and usage of each term by applied notes and explicative notes. 
In indexing practice, several types of thesauri or list of authorities are known. The most well known and used are Library of Congress Subject Headings (LCSH), from Washington, United States of America, and the French version RAMEAU, which are monolingual thesauri or encyclopedic lists of authorities. (Holley 1986; Rameau 1991; Kao 1999; Library of Congress 1999)

Thesauri are multidisciplinary because they gather terms from all sciences and subjects. Due to their encyclopedic character, thus a large volume of systematised information, this type of thesaurus is developed in a single language.

Specialised thesauri came from information indexing necessitated by certain domains. These are developed by professional associations, research institutes, or international organisations, rather than national bibliographic agencies.

In order to facilitate international information and knowledge exchange, these specialised thesauri are sometimes multilingual.

It is ideal that users apply keywords in search strategies as descriptors used in the information processing.

\section{Teaching Tips/Teaching Suggestion}

\section{Review of previous knowledge}

The need for information and known search strategies will be defined. Homework will be checked, clarifying the incorrect aspects, if any, or other student dilemmas.

\section{Warm-up}

A police story is either created or quoted from a document illustrating the presence of a very vague described suspect. After reading/describing the problem situation, students will be asked to identify the suspect. The task will not be an easy one, as the given clues will be vague, unspecific, unclear. The possibility that although many seem to be suspects, the real culprit cannot be found can also be considered.

The didactic goal of this problematic situation is to rediscover the importance of details that allow the fitting of an aspect into a particular category. It will also highlight the need to build categories of things.

Below is an example of a story with a vague outlined subject. Have the participants guess the character's job.

Denisa says she does not like the uniform, but she likes the job she has. Some think it is a boring job, but not her. The job allows her to travel a lot, both in the country and abroad. She does not have to work many hours. She can only work for 20 min and then she must take a break of at least an hour. Before starting work, she is preparing for a long time. She spends a lot of time in the company of influential people or leading people in the country and abroad.

In some months, she gains enormous amounts of money, in other months she earns very little. This money fluctuation has her a little worried and does not allow her to assume buying a house because that would require a credit. She also says that 
the job still has other financial disadvantages. For example, she has to pay for certain services that she does not use frequently, but she has to pay them monthly.

But it is a challenging job that does not bore her, but rather stimulates her to become better all the time. Another advantage of the job is that she can do something else while she does not have to work. She might even get a second job, but she still does not feel ready for this step now. It is a great joy for her because she can spend more time with her family and her two dogs.

After this moment, the topic to be addressed and the objectives of the course will be announced.

\section{Teaching Activities}

\section{Game with types of information}

The group of participants is divided into groups. The number of groups that will be set may vary depending on the number of participants. Students are given definitions of types of information, without examples.

It is recommended that the types of information made available are as diverse as possible. Students will be provided with both primary and secondary works. The necessary materials are: works of various types (such as: brochure, treatise, monograph, handbook, glossary, dictionary, map, atlas, album, symposia, report, shopping catalogue, leaflet, technical documentation, analytical bibliography, library catalogue, publication index, alphabetic index, analytic essay, or indicative essay), A3 cardboard, glue, markers, and scissors.

A competitive game with a time limit can be organised. The duration of the activity will be $15 \mathrm{~min}$. The team that recognises and places most types of information correctly wins. Answer all questions before starting the game. All groups will be congratulated for involvement and applauded. After the game is finished, document placement errors in the related categories can be discussed. Through discussion of placement errors, the characteristics of the types of information will be discussed and inclusion in certain categories will be explained. Finally, list the types of information, giving as many examples as possible. Time would also be saved if a scheme with information types is already in place.

For teaching the item and information cataloguing section, participants can be divided into five groups. We can choose five colours, for example: red, yellow, blue, green, and purple. We can place the colour cards on five different tables. We will ask the participants to move to their preferred colour and form a group with the others who chose that colour. It is advisable to have a relatively equal number of members in each group. You can suggest, depending on the size of the group, the number of team members. The five coloured cards will have one of the following topics written on the back:

- Bibliographic description of item;

- Descriptive elements; 
- Item classification;

- Indexing; or

- Thesaurus.

Envelopes will be prepared in advance for each group in which A4 sheets will be placed containing colour theme related information. In order for the task not to be too difficult, we can use the information in the theoretical summary of this chapter. If the group has certain characteristics, including a particular interest in IL, we can also prepare additional worksheets.

The task of the participants will be to write a letter/e-mail to a young user of up to ten years of age who wants additional information about the group's theme as he has a project to be completed at school on this subject. Each member of the group will assume a role from those given by the teacher: library director, librarian, IL expert, or secretary.

Participants are given 15-20 min to complete the task. All participants' questions can be answered. Also, the teacher will act as a consultant and resource person for each group, helping them where and when necessary. At the same time, the teacher will monitor the activity of the groups and track timing. At the end of the activity, the groups will appoint one representative to read the letter. All groups will be congratulated for understanding the information and the level of creativity shown and applauded for the work done. The teacher will thank the participants for their involvement and will announce that in a minute a review time will take place.

\section{Review}

The teacher together with the students will create a scheme, on a flipchart or board, containing a logical sequence of the knowledge acquired during the lesson. The activity has the role of imprinting on the minds of trainees the essential concepts, facilitating the learning of concepts from the lesson. The time set will be one minute. If writing these concepts takes too long, the scheme can be prepared before the course begins, and at the time of review, it can be brought into sight of the students and passed orally.

Also in this time, participants will be asked to express any concerns, blurs or dilemmas. The teacher will respond if time permits. If the time needed to respond is longer than the that available, a short answer will be given and a detailed explanation will be promised at the beginning of the next lesson. 


\section{Applications}

1. Discover the cataloging system for public and university libraries. Write down what this system is and what the main features are.

2. Identify the number of publications that one of the public or university libraries has in the classroom related to your field of study

3. List the functions of a thesaurus, or list of authorities

\section{Evaluation}

\begin{tabular}{|l|l|}
\hline How did you feel today? & \\
\hline What did you learn today? & \\
\hline What would you like to discover? & \\
\hline What were your strengths today? & \\
\hline $\begin{array}{l}\text { What aspects do you think you should improve } \\
\text { in your work? }\end{array}$ & \\
\hline Did you get involved in teamwork? & \\
\hline What was the value added by you to the team? & \\
\hline
\end{tabular}




\section{References}

GUIDE D'INDEXATION RAMEAU. (1991). Paris: Bibliothèque Nationale, Centre de coordination bibliographique et technique CNCIM (p. 238).

Holley, R. P. (1986). Clasificarea în SUA. In International classification (Vol. 13, no. 2, pp. $73-$ 78). Munchen.

Kao, M. L. (1999). Cataloging and classification for library technicians, New York (p. 137). London: The Haworth Press.

Library of Congress Subject Headings. (1999) $\left(22^{\text {nd }}\right.$ edn.). Washington, D.C.: Library of Congress, Cataloging Distribution Service.

\section{Webography}

UDC Consortium-About UDC. (2019). Udcc.Org. Retrieved February 15, 2019 from http:// www.udcc.org/index.php/site/page?view=about.

\section{Bibliographic Recommendations}

Conference, American, and Public Conference. (2019). "DDC 23 Summaries". OCLC. Retrieved February 15, 2019 from https://www.oclc.org/en/dewey/features/su.

External Arrangement and Description Standards|Society of American Archivists. (2019). Www2. Archivists.Org. Retrieved February 15, 2019 from https://www2.archivists.org/standards/e.

Functional Requirements for Bibliographic Records. (2015). IFLA Universal Bibliographic Control and International MARC Programme Staff (Editor); IFLA Section on Cataloguing Standing Committee (Contribution by). ISBN: 9780838913451.

Library of Congress Classification. (2019). Loc.Gov. Retrieved February 15, 2019 from https:// www.loc.gov/catdir/cpso/lcc.html.

Open Access This chapter is licensed under the terms of the Creative Commons Attribution 4.0 International License (http://creativecommons.org/licenses/by/4.0/), which permits use, sharing, adaptation, distribution and reproduction in any medium or format, as long as you give appropriate credit to the original author(s) and the source, provide a link to the Creative Commons license and indicate if changes were made.

The images or other third party material in this chapter are included in the chapter's Creative Commons license, unless indicated otherwise in a credit line to the material. If material is not included in the chapter's Creative Commons license and your intended use is not permitted by statutory regulation or exceeds the permitted use, you will need to obtain permission directly from the copyright holder. 